\title{
PENYELENGGARAAN PENDIDIKAN INKLUSI PADA JENJANG SD, SMP, DAN SMA DI KABUPATEN SIDOARJO
}

\section{THE IMPLEMENTATION OF INCLUSION EDUCATION ASSISTANCE FOR ELEMENTARY, JUNIOR HIGH, AND SENIOR HIGH SCHOOL IN SIDOARJO REGENCY}

\author{
Anggun Dyah Anjarsari, Mohammad Efendy, Sulthoni \\ Pendidikan Luar Biasa FIP Universitas Negeri Malang 2015 \\ Email : plb@fip.um.ac.id dan anggun.maichi@yahoo.com
}

\begin{abstract}
Abstrak
Masih terdapat anak berkebutuhan khusus tidak bersekolah dan tidak mendapatkan pendidikan karena jarak sekolah yang jauh. Oleh karena itu di setiap kecamatan wajib memiliki sekolah inklusi di setiap tingkat pendidikan . Tujuan dari penelitian ini secara umum di fokuskan pada bagaimana penyelenggaraan Model Pendidikan Inklusi di Sidoarjo di tingkat SD, SMP dan SMA serta faktor penghambat dan pendukung Pendidikan Inklusi. Metode yang di gunakan adalah deskriptif kuantitatif dengan sampel 23 sekolah inklusi di sidoarjo. Dari hasil penelitian, para tenaga pendidik masih banyak yang belum melakukan modifikasi, omisi, sibtitusi dan duplikasi pada materi pembelajaran, strategi dan media pembelajaran dalam model kelas layanan pendidikan inklusi.
\end{abstract}

\begin{abstract}
Abstrack
Many children with special need can't go to school and get a proper education because of the distance of the school which is too far. Because of that, every regency should has at least one inclusion school for every level of education in a sub district. Considering the analysis context, the researcher is going to study the inclusion education assistance model which are used in Sidoarjo Regency and also the supporting and inhibiting factors. The methodology which is used in this research is qualitative descriptive qualitative. The researcher uses 23 sample school in Sidoarjo. the results of research, many teachesrs not to modifications, omissiions, substitutions, and duplication instructional strategis and media in the classroom model of inclusive education.
\end{abstract}

Kata Kunci : Pendidikan Inklusi, Model Pendidikan Inklusi, Faktor Pendukung dan Faktor Penghambat Pendidikan Inklusi

Key words : Inclusion Education, Inclusion Education Model, Supporting and inhibiting factor of Inclusion Education.

\section{PENDAHULUAN}

Pendidikan berkaitan erat hubungannya dengan manusia atau mahluk hidup yang berakal sebagai pendidik atau peserta didik. Pendidikan adalah bagian penting dalam pembentukan seorang manusia menjadi seseorang yang lebih baik dari berbagai aspek sisi kehidupan. Pendidkan merupakan hak dasar untuk semua individu, bahkan untuk segala situasi dan kondisi dari suatu individu tersebut, 
karena pendidikan ialah fondasi untuk pembelajaran seumur hidup. Dengan memperoleh ilmu pengetahuan di harapkan individu mampu mengembangkan potensi yang di miliki sehingga dapat bersaing dengan masyarakat. Oleh karena itu pendidikan merupakan kebutuhan wajib bagi semua individu, termasuk untuk Anak Berkebutuhan Khusus (ABK). Selama ini anak berkubutuhan khusus mengikuti pendidikan yang sesuai dengan kelainannya. Secara tidak langsung hal ini telah mendeskriminasi anak berkabutuhan khusus, akibatnya menghambat proses saling mengenal antara anak reguler dengan anak berkebutuhan khusus. Dampaknya anak berkebutuhan khusus menjadi tersingkirkan dalam berinteraksi dengan masyarakat. Bersamaan dengan berkembangnya tuntutan anak berkebutuhan khusus dalam menyuarakan hak-haknya, serta berdasarkan pemenuhan hak atas pendidikan bagi seluruh anak di Indonesia maka muncullah konsep pendidikan inklusi. Pemenuhan hak setiap anak untuk memperoleh pendidikan juga tercantum dalam Undang-Undang Dasar Negara Republik Indonesia Tahun 1945 Pasal 31 ayat (1), mengatakan bahwa setiap warga negara berhak mendapatkan pendidikan, ayat (2) bahwa setiap warga negara wajib mengikuti pendidikan dasar dan pemerintah wajib membiayayainya.

Berkaitan dengan upaya pemenuhan hak pendidikan tanpa deskriminasi muncullah pendidikan inklusi. Menurut Sunaryo (2009) "Pendidikan inklusi merupakan suatu pendidikan, dimana semua siswa dengan kebutuhan khusus diterima di sekolah reguler yang berlokasi di daerah tempat tinggal mereka dan mendapatkan berbagai pelayanan pendukung dan pendidikan sesuai dengan kebutuhanya". Sebagaimana yang ditegaskan melalui surat edaran Dirjen

Dikdasmen No.380 tahun 2003 yang menyatakan "Pendidikan inklusi merupakan pendidikan yang mengikut sertakan anak-anak yang memiliki kebutuhan khusus untuk belajar bersama-sama dengan anak normal lainya. Pelaksanaan atau penyelenggaraan pendidikan inklusi merupakan salah satu syarat yang harus terpenuhi untuk tatanan pendidikan yang berbasis inklusi. Terdapat anak berkebutuhan khusus tidak bersekolah dan tidak mendapatkan pendidikan karena jarak sekolah yang jauh. Oleh karena itu disetiap kabupaten idealnya memiliki sekolah inklusi paling tidak satu sekolah di semua tingkat dalam satu kecamatan. Sidoarjo adalah salah satu kota di jawa timur yang di tunjuk dinas sebagai kota Inklusi. Oleh karena itu di setiap kecamatan di Sidoarjo wajib memiliki sekolah inklusi di setiap tingkat pendidikan. Sebagai sekolah yang sudah di tunjuk dinas menjadi sekolah inklusi, tentunya banyak hal yang harus di persiapkan dalam rangka penyelenggaraan pendidikan inklusi.Setiap sekolah mempunyai model layanan pendidikan inklusiyang berbeda-beda, tergantung kebutuhan siswa. Melihat kondisi dan system pendidikan yang berlaku di Indonesia, model pendidikan inklusif yang lebih sesuai adalah model yang mengasumsikan bahwa inklusi sama dengan mainstreaming, seperti pendapat Vaughn, Bos \& Schumn(dalam effendi, 2013:22). Penempatan anak berkelainan di sekolah inklusi dapat dilakukan dengan berbagai model sebagai berikut: (1) Kelas 
reguler (inklusi penuh) yaitu anak berkelainan belajar bersama anak lain (normal) sepanjang hari di kelas reguler dengan menggunakan kurikulum yang sama, (2) Kelas reguler dengan cluster yaitu anak berkelainan belajar bersama anak lain (normal) di kelas reguler dalam kelompok khusus, (3) Kelas reguler dengan pull out yaitu anak berkelainan belajar bersama anak lain (normal) di kelas reguler namun dalam waktu-waktu tertentu ditarik dari kelas reguler ke ruang sumber untuk belajar dengan guru pembimbing khusus, (4) Kelas reguler dengan cluster dan pull out yaitu anak berkelainan belajar bersama anak lain (normal) di kelas reguler dalam kelompok khusus, dan dalam waktu-waktu tertentu ditarik dari kelas reguler ke ruang sumber untuk belajar dengan guru pembimbing khusus, (5) Kelas khusus dengan berbagai pengintegrasian yaitu anak berkelainan belajar di dalam kelas khusus pada sekolah reguler, namun dalam bidang-bidang tertentu dapat belajar bersama anak lain (normal) di kelas reguler, (6) Kelas khusus penuh yaitu Anak berkelainan belajar di dalam kelas khusus pada sekolah reguler. Dari pengertian di atas bisa di simpulkan bahwa terdapat sekkolah luar biasa ( SLB ) di dalam sekolah Inklusi. Jadi peserta didik berkebutuhan khusus hanya belajar di ruang khusus tanpa belajar di ruang reguler. sehingga kurikulum yang di gunakan di sesuiakan dengan siswa berkebutuhan khusus dan guru yang mengajar harus memiliki latar belakang S1 Pendidikan Luar Biasa.

Hampir di setiap kecamatan di kota Sidoarjo sudah memiliki sekolah inklusi baik di tingkat SD, SMP maupun SMA. Namun pada kenyataan di lapangan banyak sekali hambatan-hambatan yang di temukan dalam rangka penyelenggaraan pendidikan inklusi. Sejak kota Sidoarjo di deklarasikan sebagai kota inklusi pada tahun 2006, hendakya sosialisasi tentang apa dan bagaiman pendidikan inklusi sudah cukup di mengerti oleh semua masyarakat terutama kepada sekolah dan pendidik. Kenyataannya ada beberapa sekolah yang sudah di tunjuk sebagai sekolah inklusi belum memenuhi seluruh komponen inklusi . Peneliti sebelumnya pernah melakukan observasi di dua SMP Inklusi di Sidoarjo kecamatan Gedangan, terdapat sekolah yang belum memiliki Guru Pembimbing Khusus (GPK) sebagai salah satu komponen inklusi. Selain itu fasilitas yang terdapat di sekolah tersebut di rasa kurang memberikan keamanan dan kemudahan bagi Peserta didik berkebutuhan khusus. Saat peneliti bertanya di sekolah tersebut menggunakan model inklusi apa, para pendidik masih kebingungan menjawabnya. Banyak pendidik yang belum mengerti tentang model-model inklusi yang ada di Indonesia. Padahal model inklusi adalah dasar dari pendidikan Inkluisi, apabila pihak sekolah mengetahui model inklusi apa yang di gunakan di sekolah tersebut, maka pendidik akan lebih mudah memberikan layanan dan memenuhi komponenkomponen inklusi.Guru yang menangani siswa berkebutuhan khusus juga kurang, selain itu harusnya sekolah inklusi dilengkapi dengan ruangan interaksi khusus siswa berkebutuhan khusus dan penunjang lainnya. Mengingat ruangan interaksi antara GPK dan ABK sangat penting sebagai saranabagi Anak Berkebutuhan Khusus 
melakukan konsultasi saat mengalami kesulitan di kelas. Dalam model layanan inklusiBentuk kelas reguler dengan pull out, Bentuk kelas reguler dengan cluster dan pull out, Bentuk kelas khusus dengan berbagaipengintegrasian, akan sangat bergantung kepada ruangan tersebut. Selain itu, masalah lain yang sering muncul yaitu, masih belum pahamnya para pendidik di sekolah Inklusi tentang model layanan yang harus di berikan oleh peserta didik, apakah peserta didik harus mengikuti model layanan kelas penuh, atau di tarik keluar saat pelajaran tertentu.

Melihat analisis konteks di atas peneliti bermaksud mengadakan penenlitian tentang "Penyelenggaraan Model Layanan Pendidikan Inklusi Pada Jenjang

SD, SMP, dan SMA Se-Kabupaten Sidoarjo".Alasan peneliti melakukan Penelitian ini karena menurut hasil observasi dan informasi berita,masih banyak kendala yang di temukan dalam penyelenggaraan pendidikan Inklusi terutama tentang pehamahan pendidik mengenai model pendidikan Inklusi. Selain itu permasalahan yang sering muncul yaitu, masih belum pahamnya para pendidik di sekolah Inklusi tentang model layanan yang harus di berikan kepada peserta didik, serta banyak pendidik yang belum mengetahui apa saja dan apa itu model Pendidikan Inklusi di Indonesia. Tujuan penelitian ini adalah untuk mendeskripsikan secara obyektif tentang pelaksanaan Model Layanan pendidikan inklusi, kendala-kendala yang dihadapi dalam pelaksanaan pendidikan inklusi di Kabupaten Sidoarjo.

Penelitian ini diharapkan dapat berguna bagi pengembangan pendidikan inklusif di Sumatera Barat, antara lain adalah:

1. Mengukur sejauh mana keberhasilan Kota Sidoarjo dalam menyelenggarakan pendidikan Inklusi. Sehingga kita dapat mengetahui perkembangan Pendidikan Inklusi di masa depan

2. Bagi Sekolah di Sidoarjo yang menyelenggarakan pendidikan Inklusi mampu mempertahankan dan terus melakukan perbaikan agar mutu pendidikan semakin meningkat. Bagi Sekolah di Sidoarjo yang belum menyelenggarakan pendidikan Inklusi di harapkan dapat segera menyelenggarakan Penddiikan Inklusi.

3. Sebagai kajian khususnya yang berkaitan dengan Ilmu Pendidikan Inklusi dari umum ke khusus

4. Dapat di gunakan sebagai bahan informasi yang dapat di gunakan untuk mengembangkan Ilmu Penyelenggaraan Pendidikan Inklusi

5. Sebagai bahan referensi dalam melakukan penelitian yang serupa atau penelitian lanjutan dengan mengembangkan ilmu pengetahuan khususnya yang berkaitan dengan penelitian ini

6. Agar seluruh lapisan masyarakat memahami bahwa pendidikan adalah hak setiap anak, termasuk anak berekebutuhan khusus. Sehingga segenap lapisan masyarakat sebaiknya turut mendukung adanya pendidikan 


\section{METODE}

Penelitian ini di lakukan di kabupaten Sidoarjo dengan menggunakan metode deskriptif kuantitatf dengan prosentase. Metode ini di sebut metode kuantitatif karena data penenlitian berupa angka-angka dan analisis menggunakan statistik (Sugiyno, 2010:13). Penelitian Deskriptif dapat dilakukan secara kuantitatif agar dapat dilakukan analisis statistik

Menurut Sugiyono (2010: 14) Metode penelitian kuantitatif dapat di artikan sebagai metode penelitian yang berlandaskan pada filsafat positivisme, di gunakan untuk meneliti pada populasi atau sampel tertentu, teknik pengambilan sampel pada umumnya di lakukan secara random, pengumpulan data menggunakan instrumen penelitian, analisis data bersifat kuantitatif/ statistik dengan tujuan menguji hipotesis yang telah di tetapkan. Variabel dalam penenlitian ini adalah penyelenggaraan Model Layanan Pendidikan Inklusi, sehingga sub-sub variabel yang menjadi fokus Penelitian adalah Model Layanan Pendidikan Inklusi, Faktor Pendukung Pendidikan Inklusi dan Faktor Penghambat Pendidikan Inkusi

Populasi penelitian ini adalah seluruh sekolah SD, SMP, dan SMA yang menyelenggarakan Pendidikan Inklusi. Total seluruh populasi dalam peneltian ini adalah 105 sekolah yang tersebar di 18 kecamatan. SD Inklusi di Kabupaten Sidoarjo berjumlah 74 Sekolah, SMP Inklusi di Kabupaten Sidoarjo berjumlah 24, dan SMA di kabupaten sidoarjo berjumlah 7 sekolah. Pemilihan sampel menggunkan teknik Cluster Sampling (Area Sampling ). Menurut sugiyono (2010: 121) teknik sampling yaitu. Teknik sampling daerah di gunakan untuk menentukan sampel bila objek yang akan di teliti atau sumber data sangat luas, misalnya penduduk dari suatu negara, propinsi, atau kabupaten.untuk menentukan penduduk mana yang akan di jadikan sumber data, maka pengambilan sampelnya berdasarkan daerah populasi yang telah di tetapkan.

Teknik sampling daerah ini sering di gunakan melalui dua tahap, yaitu tahap pertama menentukan sampel daerah atau dalam penelitian ini menentukan kecamatan. Tahap kedua menentukan orang-orang yang ada pada daerah itu secara sampling juga atau dalam penelitian ini sekolah inklusi yang akan dijadikan sampel.

Instrumen pengumpulan data di lakukan dengan angket dan dokumentasi. Angket atau kuisioner merupakan suatu teknik atau cra pengumpulan data secara tidak langsung (peneliti tidak langsung bertanya-tanya kepada responden). Instrumen atau alat pengumpulan datanya juga di sebut angket berisi sejumlah pertanyaan atau pernyataan yang harus di jawab atau di respon oleh responden". (Sudaryono, 2012: 30). "Metode analisis dokumen ini merupakan metode utama atau primer apabila peneliti melakukan pendekatan analisis isi (content analisist). Untuk penelitian dengan pendekatan 
lain, metode ini mempunyai kedudukan yang penting. Data yang di peroleh dari analisi dokumen dapat digunakan sebagai data pendukung atau pelengkap”. (Sudaryono, 2012: 41)

Analisis data yang akan di hasilkan ditempuh dengan menggunakan beberapa seperti yang di kemukakan oleh Hadeli (2004:24) yakni editing,

Pengkodean, dan Tabulasi. "Metode analisis yang digunakan dalam penelitian ini adalah Analisis Deskriptif Persentase. Deskriptif persentase ini diolah dengan cara frekuensi dibagi dengan jumlah skor maksimal 100 persen”, seperti dikemukan Sudjana (2001: 129) adalah sebagaiberikut:

$$
\begin{aligned}
& \mathrm{P}=\mathrm{F} \times 100 \% \\
& \text { Keterangan : } \\
& \mathrm{P}: \text { Persentase } \\
& \mathrm{F}: \text { Frekuensi } \\
& \mathrm{N} \text { : Jumlah responde } \\
& \text { 100\% : Bilangan tetap }
\end{aligned}
$$

Penghitungan deskriptif persentase ini mempunyai langkah-langkah sebagai berikut:

a. Mengkoreksi jawaban kuesioner dari responden

b. Menghitung frekuensi jawaban YA dari responden

c. Jumlah skor maksimal

d. Masukkan ke dalam rumus.

Persentase dari tiap-tiap kategori:

$$
\frac{\text { Jumlah responden dengan kategori YA } \quad \text { X 100\% }}{\text { Jumlah skor maksimal }}
$$

\section{HASIL}

Dari seluruh analisis di atas, hasil perhitungan tiap-tiap model pendidikan Inklusi akan di sajiakan dalam bentuk grafik dengan menggunakan rumus sebagai berikut :

$$
\text { Jumlah skor rill seluruh model X 100\% }
$$

Jumlah Skor max 


\section{A. Model Layanan Pendidikan Inklusi}

\begin{tabular}{|c|c|c|c|c|c|c|}
\hline & \multicolumn{3}{|c|}{ Jumlah Jawaban ( Skor Rill) } & \multicolumn{3}{|c|}{ Hasil Penghitungan } \\
\hline Model Layanan Pendidikan Inklusi & SD & SMP & SMA & SD & SMP & SMA \\
\hline 1. Model Kelas Reguler & $46 \%$ & $60 \%$ & $100 \%$ & $16 \%$ & $22 \%$ & $35 \%$ \\
\hline $\begin{array}{l}\text { 2. Model Kelas Reguler dengan } \\
\text { Cluster }\end{array}$ & $40 \%$ & $80 \%$ & $66 \%$ & $14 \%$ & $28 \%$ & $22 \%$ \\
\hline $\begin{array}{l}\text { 3. Model Kelas Reguler dengan } \\
\text { Pull Out }\end{array}$ & $80 \%$ & $60 \%$ & $33 \%$ & $28 \%$ & $22 \%$ & $11 \%$ \\
\hline $\begin{array}{l}\text { 4. Model Kelas Reguler dengan } \\
\text { Cluster dan Pull Out }\end{array}$ & $66 \%$ & $40 \%$ & $33 \%$ & $23 \%$ & $14 \%$ & $11 \%$ \\
\hline $\begin{array}{l}\text { 5. Model Kelas Reguler dgn } \\
\text { Berbagai Pengintegrasian }\end{array}$ & $40 \%$ & $20 \%$ & $33 \%$ & $14 \%$ & 75 & $11 \%$ \\
\hline 6. Model Kelas Khusus & $13 \%$ & $20 \%$ & $33 \%$ & $5 \%$ & $7 \%$ & $11 \%$ \\
\hline Skor Maxsimal & 285 & 280 & 298 & $100 \%$ & $100 \%$ & $100 \%$ \\
\hline
\end{tabular}

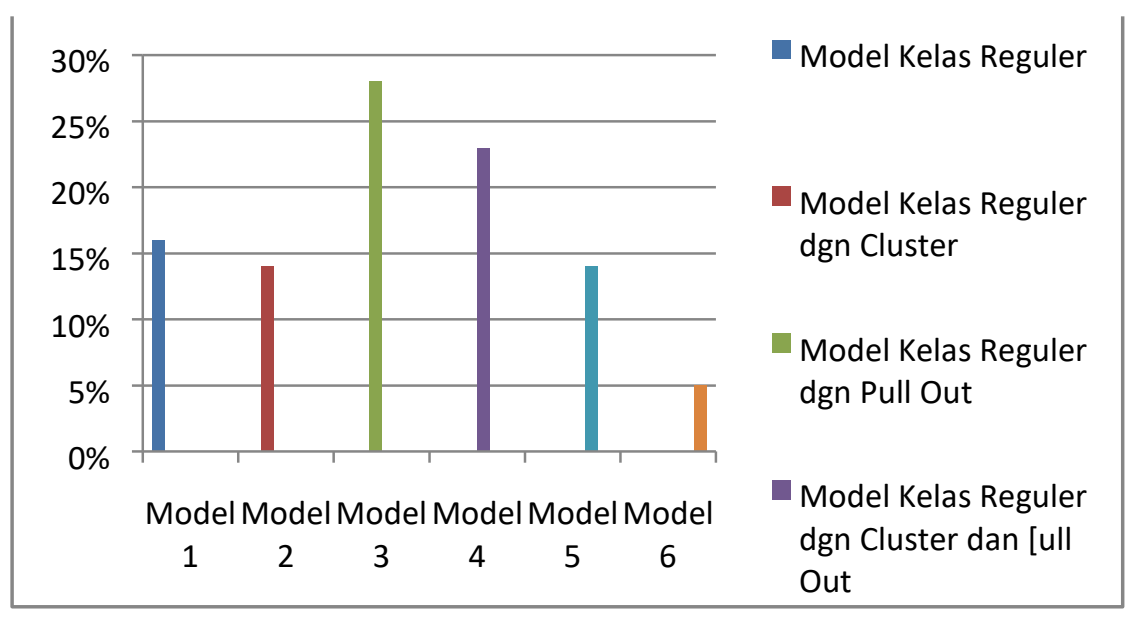

\section{Gambar 4.1 Prosentase Model Layanan Pendidikan Inklusi Pada Jenjang SD di Sidoarjo}

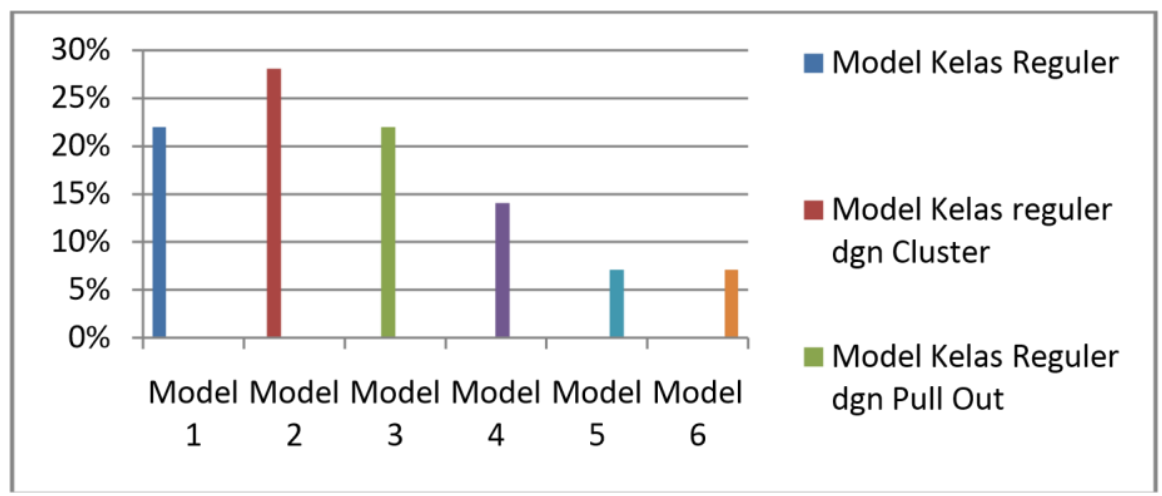

Gambar 4.2 Prosentase Model Layanan Pendidikan Inklusi Pada Jenjang SMP di Sidoarjo 


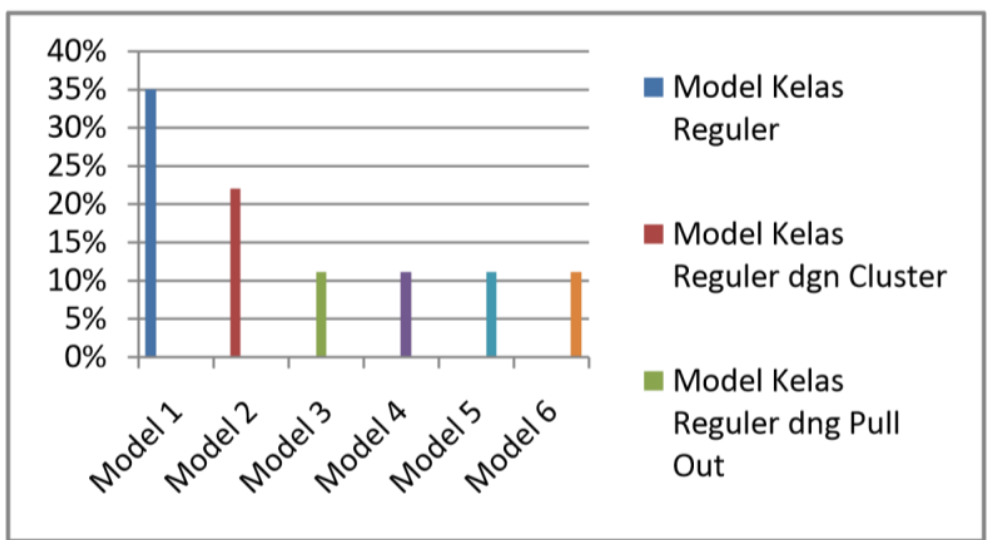

\section{Gambar 4.3 Prosentase Model Layanan Pendidikan Inklusi Pada Jenjang SMA di Sidoarjo}

\section{B. Penghitungan Keseluruhan Faktor Penghambat Pendidikan Inklusi}

\begin{tabular}{|c|c|c|c|c|c|c|}
\hline \multirow[t]{2}{*}{ Faktor Pendukung Pendidikn Inklusi } & \multicolumn{3}{|c|}{ Jumlah Jawaban ( Skor Rill ) } & \multicolumn{3}{|c|}{ Hasil Penghitungan } \\
\hline & SD & SMP & SMA & SD & SMP & SMA \\
\hline $\begin{array}{l}\text { 1. Sikap, Komitmen dan } \\
\text { Keyakinan }\end{array}$ & $80 \%$ & $80 \%$ & $100 \%$ & $23 \%$ & $29 \%$ & $29 \%$ \\
\hline 2. Sarana dan Prasarana & $66 \%$ & $60 \%$ & $80 \%$ & $19 \%$ & $21 \%$ & $22 \%$ \\
\hline 3. Tenaga Pendidik & $73 \%$ & $80 \%$ & $80 \%$ & $21 \%$ & $29 \%$ & $22 \%$ \\
\hline 4. Sistem Pembelajaran & $46 \%$ & $20 \%$ & $33 \%$ & $13 \%$ & $7 \%$ & $10 \%$ \\
\hline 5. Dukungan Masyarakat & $86 \%$ & $40 \%$ & $66 \%$ & $24 \%$ & $14 \%$ & $18 \%$ \\
\hline Skor Maxsimal & 351 & 280 & 359 & $100 \%$ & $100 \%$ & \\
\hline 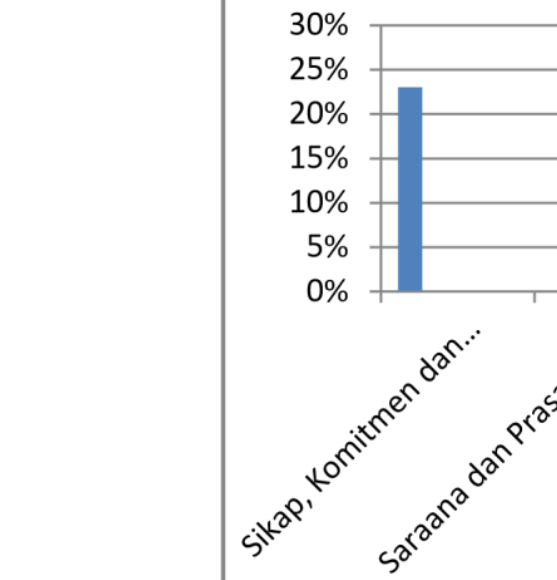 & $r^{2}$ & $e^{r^{r}}$ & $8 s_{0}^{0}$ & & & \\
\hline
\end{tabular}

Gambar 4.4 Faktor Pendukung Pendidikan Inklusi Di Sidoarjo Pada Jenjang SD 


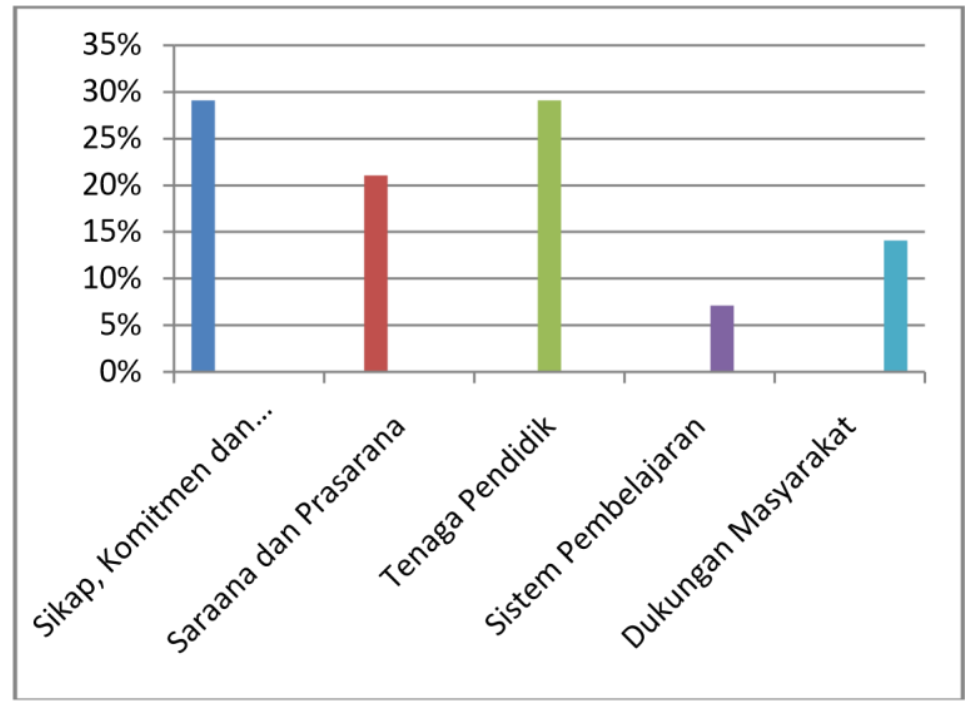

Gambar 4.5 Faktor Pendukung Pendidikan Inklusi Di Sidoarjo Pada Jenjang SMP

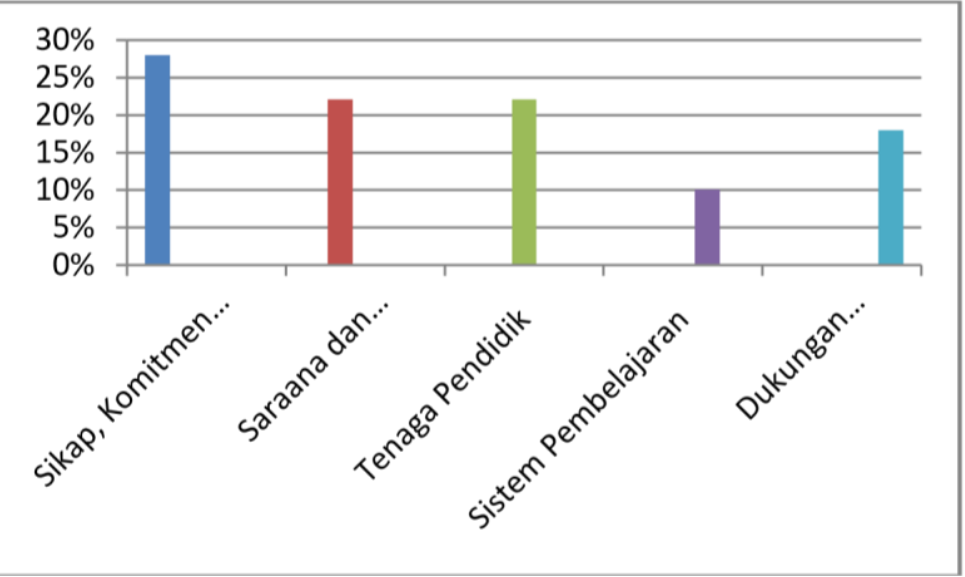




\section{Gambar 4.6 Faktor Pendukung Pendidikan Inklusi Di Sidoarjo Pada Jenjang SMA}

\section{Penghitungan Keseluruhan Faktor Penghambat Pendidikan Inklusi}

\begin{tabular}{|c|c|c|c|c|c|c|}
\hline & \multicolumn{3}{|c|}{ Jumlah Jawaban ( Skor Rill ) } & \multicolumn{3}{|c|}{ Hasil Perhitungan } \\
\hline Faktor Penghambat Pendidikan Inklusi & SD & SMP & SMA & SD & SMP & SMA \\
\hline 1. Sikap Negatif Warga Sekolah & $46 \%$ & $40 \%$ & $33 \%$ & $22 \%$ & $20 \%$ & $14 \%$ \\
\hline $\begin{array}{c}\text { 2. Kurangnya Kerjasama antara } \\
\text { Sekolah Inklusi dan SLB }\end{array}$ & $53 \%$ & $60 \%$ & $66 \%$ & $25 \%$ & $30 \%$ & $29 \%$ \\
\hline 3. Sikap Peserta Didik & $40 \%$ & $20 \%$ & $33 \%$ & $19 \%$ & $10 \%$ & $14 \%$ \\
\hline $\begin{array}{c}\text { 4. Keterbatasan Dana dan } \\
\text { Tenaga Pendidik }\end{array}$ & $73 \%$ & $80 \%$ & $100 \%$ & $34 \%$ & $40 \%$ & $43 \%$ \\
\hline Skor Maxsimal & 212 & 200 & 232 & $100 \%$ & $100 \%$ & $100 \%$ \\
\hline
\end{tabular}

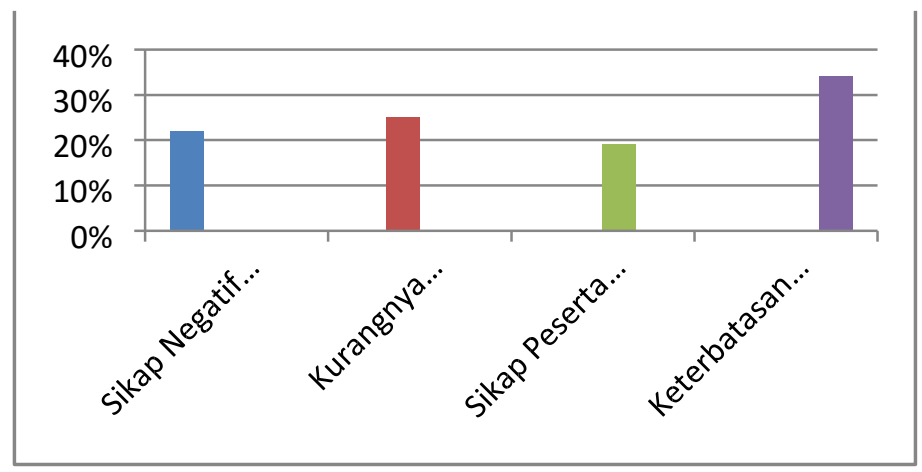

Gambar 4.7 Faktor Penghambat Pendidikan Inklusi Di Sidoarjo Pada Jenjang SD

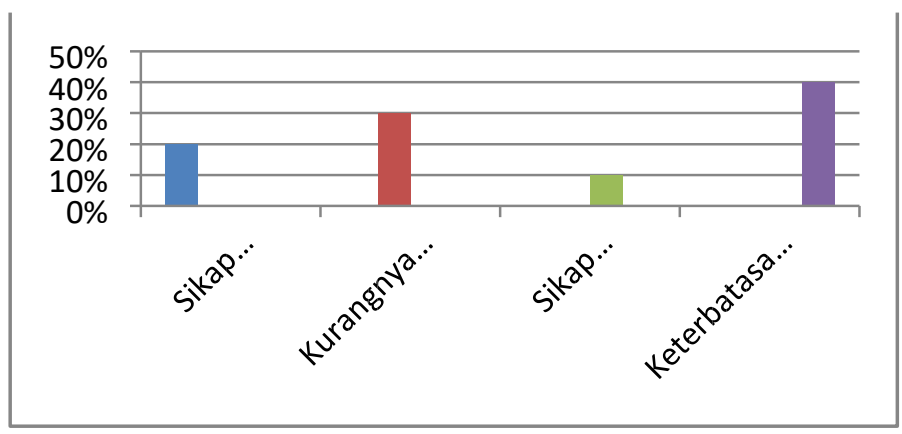

Gambar 4.8 Faktor Penghambat Pendidikan Inklusi Di Sidoarjo Pada Jenjang SMP 


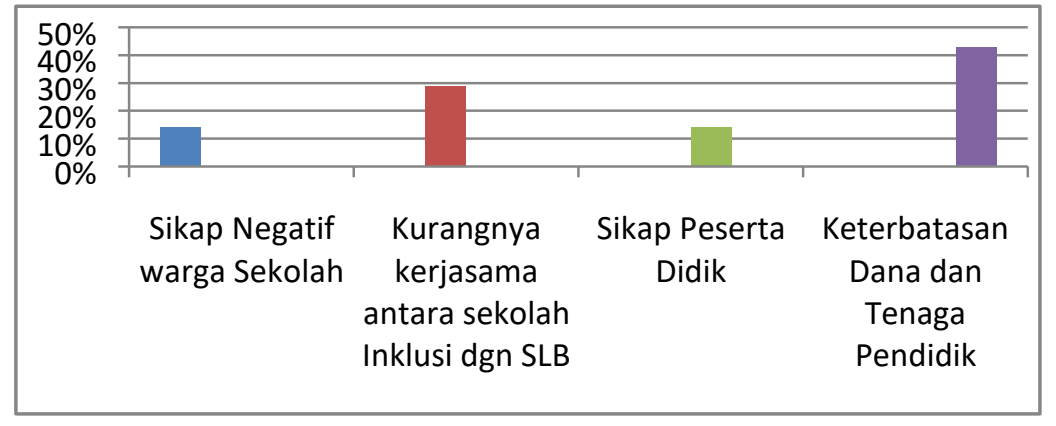

\section{Gambar 4.9 Faktor Penghambat Pendidikan Inklusi Di Sidoarjo Pada Jenjang SMA}

\section{PEMBAHASAN}

Hasil penelitian di atas tentang Penyelenggaraan Model Layanan Pendidikan Inklusi di Sidoarjo pada Jenjang SD, SMP, dan SMA yang pengupulan datanya melalui angket yang d sebar di 23 sekolah Inklusi di Kabupaten Sidoarjo adalah sebanyak 80\% pada jenjang SD Menggunakan Model Kelas Reguler dengan Pull Out. Dari hasil penelitian, Model Kelas reguler dengan Pull Out paling banyak di gunakan pada jenjang SD. Banyak SD yang menggunakan model ini karena peserta didik berkebutuhan khusus sering mengikuti pembelajaraan yang di rasa sulit di ruang sumber. Peserta didik berkebutuhan khususu pada jenjang SD masih sangat membutuhkan pendampingan GPK dan suasana yang tenang untuk mampu berkonsentrasi. Sehingga, masih banyak peseta didik berkebutuhan khusus menggunakan ruangan sumber. Beberapa sekolah mengatakan rata-rata mata pelajaran matematika, bahasa inggris, dan IPS yang sering di laksanakan di ruang sumber. Baik pada jam pelajaran berlangsung atau seusai sekolah. Untuk peserta didik berkebutuhan khusus dengan tunagrahita dan autis, biasanya memnang layanan di ruang sumber di lakukan secara individu.

Pada sekolah Jenjang SMP di Sidoarjo sebanyak 80\% menerapkan Model Kelas Reguler dengan Cluster. Dari penuturan berbagai responden, alasan mengapa Model ini banyak di terapkan pada jenjang SMP yakni (1) jumlah GPK yang terbatas sehingga untuk menangani Peserta didik berkebutuhan khusus apabila tudak di jadikan satu akan kesulitan mengatur jam dan waktunya (2) kebanyakan peserta didik dengan kelaianan low visio dan dislexia yang di jadikan satu, untuk kelainan yang berat seperti autis dipisah (3) interaksi sosial peserta didik berkebutuhan khusus pada jenjang SMP juga cukup bagus sehingga tidak berpengaruh apabila di kelompokkan dengan peserta didik berkebutuhan khusus lainnya. Selain pertnyataan di atas, pada jenjang SMP guru-guru lebih berusaha menempatkan peserta didik berkebutuhan khusus di kelas reguler penuh, kecuali untuk autis dan tunagrahita yang sedang. Model Kelas Reguler dan Model Kelas Reguler dengan Cluster ini apabila di terapkan secara penuh akan berpengaruh sangat besar terhadap kemampuan interaksi sosial 
bagi anak berkebutuhan khusus. Serta menumbuhkan rasa saling mengharagai antara siswa berkebutuhan khusus dengan pserta didik normal. Agar tidak ada lagi kata deskriminasi.

Pada jenjang SMA jumlah Prosentase sebanyak 100\% menggunakan Model Kelas Reguler. Jumlah ini tentu saja jumlah yang sempurna, dari 3 sampel yang peneliti ambil. Semua sekolah pada jenjang SMA menerapkan Model Kelas Reguler. Seperti pada jenjang SMP, peserta didik pada Jenjang SMA sudah sangat mampu bersosialisai dengan tean sebaya dan mampu mengikuti kegiatan pembelajaran dengan baik. Peserta didik berkebutuhan khusus yang hendak masuk ke Sekolah Inklusi jenjang SMA harus rekomendasi atau pada saat SMP sudah bersekolah di inklusi pula. Sehingga peserta didik berkebutuhan khusus ini sudah memiliki pengalaman tentang cara beradaptasi dan berinteraksi.

Menurut penelitian melalui penyebaran angket, sebanyak 86,65 faktor pendukung pendIdikan inklusi di SD adalah Dukungan dari Masyarakat. Banyak masyarakat yang sudah di libatkan dalam berbagai kegiatan yang di adakan oleh Sekolah Penyelenggara Penddiikan Inklusi. Warga sekitar juga turut mendukung pendidikan inklusi, misalnya ada waraga yang sukarela menjadi penyebrang jalan baik menyebrangkan peserta didik berkebutuhan khusus maupun peserta didik reguler.

Dari hasil penelitian menunjukkan sebanyak $80 \%$ tenaga pendidik dan sikap positif warga sekolah mulai dari kepala sekolah, guru, staf dan orang tua sudah menunjukkan, memiliki keyakianan dan komitmen yang tinggi untuk mendukung keberhasilan Pendidikan Inklusi pada jenjang SMP di Kabupaten Siodarjo. Seperti yang sudah di jelaskan komitmen guru dalam mendidik setiap siswanya sebagai kewajiban dan tugas mulia untuk mencerdaskan anak bangsa sudah sangat maksimal di Sidoarjo. namun, dalam setiap kelebihan tidak di pungkiri akan ada saja kekurangan. Sedangkan pada jenjang SMA sebanyak 100\% adalah sikap, komitmen dan keyakinan seluruh warga sekolah.

Sedangkan faktor penghambat Pendidikan Inklusi di Sidoarjo baik pada jenjang SD, SMP dan SMA adalah Keterbatasan Dana daan Tenaga Pendidik yang ahli dalam Bidangnya. Prosentase masing-masing jejang adalah $100 \%$ pada jenjang SD dan SMA, $80 \%$ pada jenjang SMP. . Hasil ini tentu saja menjadi catatan bahwa dana dan guru yang ahli di bidangnya sangatlah kurang. Memang dari hasil penelitian banyak sekali GPK yang di bayar sangat minim oleh sekolah, dengan alasan kurangnya dana untuk membayar GPK. Selain itu, kurangnya dana untuk memebeli peralatan, media pembelajaran, dll. GPK di harapkan benar-benar lulusan S1 Pendidikan Luar Biasa agar dalam melakauakn pembelajran lebih maksimal. 


\section{KESIMPULAN DAN SARAN}

Dari hasil pembahasan keseluruhan model di atas dapat di simpulkan bahwa tidak semua peserta didik berkebutuhan khusus harus belajar di ruang kelas reguler. peserta didik berkebuthan khusus boleh belajar di ruangan sumber apabila di perlukan. Namun, dalam konsep sekolah inklusi yang ideal hendaknya waktu peserta didik berkebutuhan khusus lebih banyak di ruangan kelas reguler daripada di ruangan sumber. Sekolah penyelenggara Pendidikan Inklusi biasanya menempatkan peserta didik dengan autis dan tunagrahita lebih banyak di ruangan sumber, baik secara kelompok maupun individu. Untuk peserta didik berkebutuhan khusus dengan low vision, dan tunadaksa waktunya lebih banyak di ruangan kelas reguler secara individu. Para tenaga pendidik masih banyak yang belum melakukan modifikasi, omisi, sibtitusi dan duplikasi pada materi pembelajaran, strategi dan nedia pembelajran. Kejadian di atas merupakan pelanggaran yang seharusnya tidak di lakukan,. Karena modifikasi materi, kurikulum dan media pembelajaran hukumnya wajib di laksanakan. Dengan tujuan agar peserta didik berkebutuhan khusus mampu mengikuti materi yang ada sesuai kemampuan dan karakteristiknya.

Sarana dan prasarana sebagian besar di sekolah penyelenggara pendidikan inklusi masih kurang memadahi. Terbukti, masih ada sekolah yang belum memilki buku braille untuk siswa tunanetranya. Adaptasi lingkungan fisik juga masih minim. Oleh karena itu segenap warga sekolah dan anggota masyarakat wajib mendukung keberhasilan pendidika inklusi guna terciptanya pendidikan yang adil tanpa deskriminasi.

Dari hasil kesimpulan di atas, adapun saran-saran untuk pihak yang menyelenggarakan Pendidikan Inkusi, antara lain:

1. Bagi Kepala Sekolah Penyelenggara Inklusi

Bagi Kepala Sekolah yang menyelenggarakan Pendidikan Inklusi di harapkan lebih melakukan komunikasi dengan pihak-pihak yang berkaitan dengan layanan khusus, misalnya SLB, Psikiater,dll. Selain itu lebih memotivasi dan memberikan arahan kepada segenap warga sekolah untuk keberhasilan Pendidikan Inklusi.

2. Bagi Tenaga Pendidik ( GPK dan Guru Kelas )

Bagi GPK dan Guru Kelas, di harapkan lebih berkolaborasi dalam membuat RPP, PPI, serta layanan yang Kompensatoris. Para tenaga Pendidik di harapakan mampu menciptakan kondisi kelas yang hangat, kkondusif yang nyaman terutama bagi peserta didik berkebutuhan Khusus. 3 . Bagi Orang tua yang memiliki Peserta Didik Berkebutuhan Khusus Bagi orang tua yang memilki anak berkebutuhan khusus di harapakan lebih memberi kesempatan kepada anaknya unruk bersekolah di Inklusi serta memberikan dorangan dan motivasi. 
3. Masyarakat Luas

Bagi masyarakat luas di harapakan lebih meenerima keberadaan anak berkebutuhan khusus khusus sebagai bagian dari anggota masyarakat dan memberi kesempatan yang sama dengan warga normal lainnya.

\section{DAFTAR RUJUKAN}

Efendi, Muhammad. 2013. Persepektif Pendidikan Inklusi. Malang : Pendidikan Luar Biasa Univeritas Negeri Malang

Hadeli. 2006. Metode Penelitian Pendidikan. Jakarta : Quantum Teaching

Sudaryono. 2013. Pengembangan Instrumen Pendidikan. Yogyakarta : Graha Ilmu

Sugiyono. 2013. Metode Penelitian Kualitatif, Kuantitatif dan R\&D. Bandung :

Alfabeta

Sugiyono. 2013. Metode Penelitian Pendidikan. Bandung: Alfabeta.

Sunaryo. 2009. Manajemen Pendidikan Inklusi: Konsep, Kebijakan, dan implemantasinya DalamPendidikanLuaRBiasa.Online) (hhtp//filu.upi.edu/Direktori/FIP/JUR_PEND_LUAR_BIASA_Ma kalahSunaryoMakalah_Inklusif.Pdf) Diakses tanggal 4 Januari 2015 